\title{
APPROXIMATION BY NÖRLUND MEANS OF DOUBLE WALSH-FOURIER SERIES FOR LIPSCHITZ FUNCTIONS
}

\author{
KÁROLY NAGY
}

Abstract. For double trigonometric Fourier series, Móricz and Rhoades studied the rate of uniform approximation by Nörlund means of the rectangular partial sums of double Fourier series of a function belonging to the class $\operatorname{Lip} \alpha(0<\alpha \leqslant 1)$ [12] and the class of continuous functions [13], on the two-dimensional torus. As a special case, they obtained the rate of uniform approximation by double Cesàro means.

The main aim of this paper is to investigate the rate of the approximation by the Nörlund means $T_{m, n}^{w}(f)$ of double Walsh-Fourier series of a function in $L^{p}$, in particular, in $\operatorname{Lip}(\alpha, p)$, where $\alpha>0$ and $1 \leqslant p \leqslant \infty$. In case $p=\infty$, by $L^{p}$ we mean $C_{W}$, the collection of the uniform $W$-continuous functions.

Earlier results on one-dimensional Nörlund means of the Walsh-Fourier series was given by Móricz and Siddiqi [16].

Mathematics subject classification (2010): 42C10.

Keywords and phrases: Walsh group, Walsh system, Walsh-Fourier series, Nörlund mean, two-dimensional system, approximation.

\section{REFERENCES}

[1] G.H. Agaev, N.JA. Vilenkin, G.M. Dzhafarli, And A.I. Rubinstein, Multiplicative systems of functions and harmonic analysis on 0-dimensional groups, Izd. ('ELM"), Baku, (1981), (Russian).

[2] I. Blahota, G. GÁt, Norm summability of Nörlund logarithmic means on unbounded Vilenkin groups, Anal. in Theory and Appl. 24, 1 (2008), 1-17.

[3] S. Fridli, P. Manchanda, And A.H. SiddiQi, Approximation by Walsh-Nörlund means, Acta Sci. Math. (Szeged) 74 (2008), 593-608.

[4] G. Gát, U. Goginava, Uniform and L-convergence of logarithmic means of Walsh-Fourier series, Acta Math. Sinica, English Series 22, 2 (2006), 497-506.

[5] G. GÁt, U. GoginaVA, Uniform and L-convergence of logarithmic means of cubical partial sums of double Walsh-Fourier series, East Journal on Approximations 10, 3 (2004), 391-412.

[6] G. GÁt, U. Goginava, Uniform and L-convergence of logarithmic means of double Walsh-Fourier series, Georgian Math. J. 12, 1 (2005), 75-88.

[7] G. GÁt, U. Goginava, G. TKeBuChava, Convergence in measure of logarithmic means of quadratical partial sums of double Walsh-Fourier series, J. Math. Anal. Appl. 323 (2006), 535-549.

[8] G. Gát, U. Goginava, G. Tkebuchava, Convergence of logarithmic means of multiple WalshFourier series, Anal. in Theory and Appl. 21, 4 (2005), 326-338.

[9] U. Goginava, On the approximation properties of Cesàro means of negative order of Walsh-Fourier series, Journal of Approximation Theory 115 (2002), 9-20.

[10] U. Goginava, G. TKeBuchava, Convergence of subsequences of partial sums and logarithmic means of Walsh-Fourier series, Acta Sci. Math. (Szeged) 72 (2006), 159-177.

[11] M. A. JAStrebova, On approximation of functions satisfying the Lipschitz condition by arithmetic means of their Walsh-Fourier series, Math. Sb. 71 (1966), 214-226 (Russian).

[12] F. Móricz, B. E. RhoAdES, Approximation by Nörlund means of double Fourier series for Lipschitz. functions, Journal of Approx. Theory 50 (1987), 341-358. 
[13] F. MóRICZ, B. E. RhOAdes, Approximation by Nörlund means of double Fourier series to continuous functions in two variables, Constructive Approximation 3 (1987), 281-296.

[14] F. MóRICZ, F. SCHIPP, On the integrability and $L^{1}$ convergence of Walsh series with coefficients of bounded variation, Journal of Math. Anal. and Appl. 146, 1 (1990), 99-109.

[15] F. MóRICZ, F. SCHIPP, On the integrability and $L^{1}$ convergence of double Walsh series, Acta Math. Hung. 57, 3-4 (1991), 371-380.

[16] F. MóRICZ, A. SidDiQI, Approximation by Nörlund means of Walsh-Fourier series, Journal of Approx. Theory 70, 3 (1992), 375-389.

[17] F. Schipp, W. R. Wade, P. Simon, AND J. PÁL, Walsh Series. An Introduction to Dyadic Harmonic Analysis, Adam Hilger (Bristol-New York 1990).

[18] V.A. SKVORTSOv, Certain estimates of approximation of functions by Cesàro means of Walsh-Fourier series, Mat. Zametki 29 (1981), 539-547 (Russian).

[19] Sh. Yano, On Walsh series, Tohoku Math. J. 3 (1951), 223-242.

[20] Sh. Yano, On approximation by Walsh functions, Proc. Amer. Math. Soc. 2 (1951), 962-967. 